\title{
Determining the knowledge of primary healthcare (PHC) physicians and factors influencing practices in the implementation of the catch-up vaccination program in PHC clinics in Dammam, Saudi Arabia
}

Rawan S. AlFaraj, MBBS, Amal AlShehab, FAMCO fellow, SBFM, Shahid A. Latif, DPH, MMed,

Khalid J. Al Fraihi, Dip FAMCO, Fellow FAMCO.

\begin{abstract}
الأهداف : تحديد معرفة أطباء الرعاية الصحية الأولية والعوامل المؤثرة في الممارسات

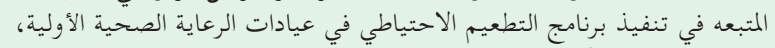

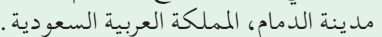

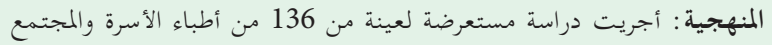

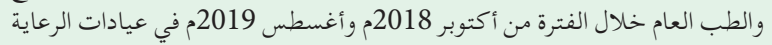

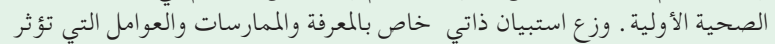

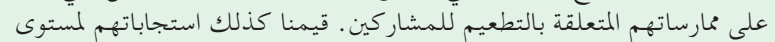

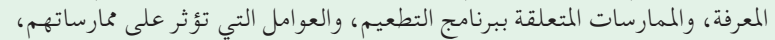

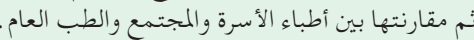

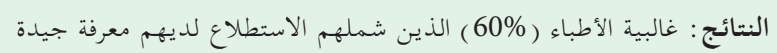

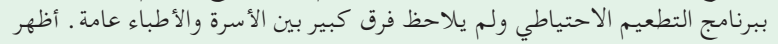

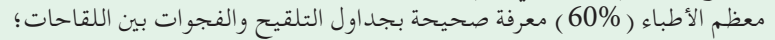

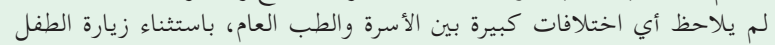

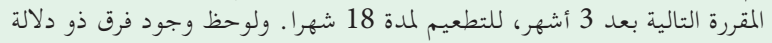

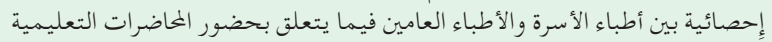

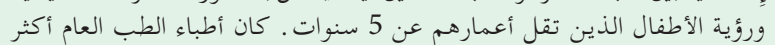
مشار كة في برنامج التطعيم.

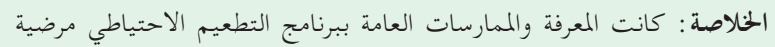

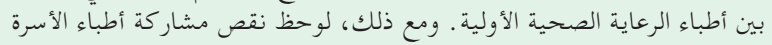

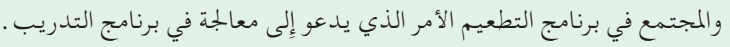

Objectives: To determine the knowledge of primary healthcare (PHC) physicians and factors influencing implementation of the catch-up vaccination program in PHC clinics in Dammam, Saudi Arabia.

Methods: A cross-sectional study was conducted with a sample of 136 general and family physicians between October 2018 and August 2019 in PHC clinics. A self-administered questionnaire related to knowledge, practices, and factors affecting their practices regarding vaccination was given to participants. Their responses were assessed for level of knowledge, practices regarding the vaccination program, and factors affecting their practices, and then compared between family and general physicians.
Results: The majority of physicians $(60 \%)$ surveyed had good knowledge of the catch-up vaccination program and no significant difference was observed between family and general physicians. Most physicians (60\%) demonstrated correct knowledge of vaccination schedules and gaps between vaccines; no significant differences were observed between family and general physicians, except for the next scheduled child visit after 3 months, for the 18-month vaccination. A statistically significant difference was observed between family and general physicians related to attending educational lectures and seeing children younger than 5 years. General physicians were more involved in the vaccination program.

Conclusion: The overall knowledge and practices of the catch-up vaccination program was satisfactory among PHC physicians. However, a lack of family physicians' involvement in the vaccination program was observed that needs to be addressed in their training program.

Keywords: childhood immunization, knowledge, catchup vaccine, primary health physicians

Saudi Med J 2020; Vol. 41 (6): 645-651 doi: 10.15537/smj.2020.6.25116

From the College of Medicine (AlFaraj, ALshehab), University of Dammam, Dammam; from the Department of Family and Community Medicine (AlFaraj, AlShehab, Latif, Al Fraihi), Armed Forced Hospital, King Abdulaziz Airbase, Dhahran. Kingdom of Saudi Arabia.

Received 19th December 2019. Accepted 12th May 2020.

Address correspondence and reprint request to: Dr. Rawan S. AlFaraj, College of Medicine, University of Dammam, Dammam, Kingdom of Saudi Arabia. E-mail: rsa2020@hotmail.com

ORCID ID: https://orcid.org/0000-0002-7562-688X 
Tmmunization is one of the most cost-effective health Interventions that can prevent serious infectious diseases. ${ }^{1}$ The World Health organization (WHO) has stated that "immunization saves millions of lives," 2 and it has been estimated that 2 to 3 million deaths per year are avoided because of immunization. This prevention can be accomplished through fair access to vaccines. ${ }^{3,4}$ However, according to the WHO, an estimated 19.5 million infants worldwide are now not receiving these lifesaving vaccines which means that these children are exposed to vaccine-preventable diseases. ${ }^{3,4}$ Since vaccination is a critical tool for preventing communicable diseases, all children should receive the required vaccinations.

The Kingdom of Saudi Arabia (KSA) is considered one of the first countries that has ensured the inclusiveness of vaccinations, with an immunization rate greater than $98 \% .{ }^{5}$ This success was achieved through a well-established healthcare system as vaccinations are provided free of charge at the point of care; vaccination is mandatory for obtaining birth certificates and before school entry. ${ }^{6,7}$

Despite the progress in individual countries and a strong global rate of new vaccine introductions, the targets for the eradication of some communicable diseases are behind schedule. ${ }^{2}$ Several studies have investigated the barriers to immunization in children in an attempt to understand why some vaccine-preventable diseases are still relatively common..$^{8-10}$ These barriers include an inadequate supply of vaccines, a lack of access to health services, a shortage of accurate information regarding immunization among providers, and insufficient political and financial support. ${ }^{11}$ Barriers which influence the immunization rate have previously been studied in Saudi Arabia including poor provider knowledge regarding immunization indications and contraindications, and parents' fear of adverse effects of vaccines. ${ }^{7,12,13}$ Although different strategies for improving vaccination coverage have been identified, achieving the levels necessary to obtain the most significant effects is a goal that will only be reached by the combined efforts of healthcare systems, providers, and parent education. ${ }^{8}$

With the goal of ensuring timely and accurate administration of vaccines, the Advisory Committee on Immunization Practices of the Centers for Disease

Disclosure. Authors have no conflict of interests, and the work was not supported or funded by any drug company.
Control and Prevention, together with the American Academy of Pediatrics and the American Academy of Family Physicians, recommended the use of an appropriate catch-up schedule for children who may have missed doses of routine childhood vaccines. As a result, healthcare professionals are facing the challenging task of establishing a catch-up schedule for those children who have missed the basic vaccination program. ${ }^{14}$

In KSA, nurses are more involved in developing the schedule for vaccinations resulting in a deficiency in knowledge and practices of vaccination among physicians. ${ }^{12}$ This study recommended more involvement of physicians in the vaccination program. Currently, the responsibility for vaccination of children is shared between general medical practices and community services. There is insufficient knowledge, inadequate training, and less interest regarding vaccination among health professionals, since general practitioners are under no obligation to vaccinate children. These factors have a substantial negative impact on the quality of vaccination services provided for children. ${ }^{?}$

Establishing a proper catch-up schedule is both a challenging and a time-consuming task, and healthcare professionals often struggle to design the schedules for children who missed their vaccinations. ${ }^{15}$ Primary healthcare (PHC) physicians are the core members of the healthcare system who deal with these cases, and are responsible for disease prevention. However, the authors found no studies conducted in Saudi Arabia that assessed the knowledge status of PHC physicians regarding the catch-up vaccination program, and the factors influencing their practices in the Eastern Province region.

This aim of this study is to identify the knowledge, practices, and factors influencing the implementation of the catch-up vaccination program in their practices and to devise strategies for improving their catch-up vaccination procedures.

Methods. A cross-sectional descriptive study was conducted between October 2018 and August 2019 in the primary healthcare clinics (PHCC) in Dammam, Eastern Province, KSA. The study population included all physicians practicing in this area. There were 159 physicians working in a total of 33 PHCC. Out of these 159,136 physicians were selected to participate in the study. A well-structured English questionnaire (Appendix 1) was developed to determine knowledge of the catch-up vaccination program and assess the practices and factors influencing implementation of the vaccination program in their clinics. The questionnaire 
was piloted with 10 physicians working in the family and community department in one of the hospitals in the Eastern Province to determine the face validity of the instrument and questions were modified accordingly. These physicians were not included in the study. Content validity was assessed by experts in area of the vaccination program. The questionnaire was comprised of 4 parts: i) the first part collected information on the demographic characteristics of the physicians participating in the study; ii) the second part included information related to vaccination practices at the PHC; iii) the third part contained questions related to the current knowledge of physicians on vaccination timing, doses of vaccine, and the interval between doses; and iv) the fourth part assessed factors influencing the practices surrounding implementation of the catch-up vaccination program.

The sample size was calculated with Raosoft program, using a margin of error of 5\% and a $95 \%$ confidence interval. A sample size of 127 general and family physicians working in PHC clinics was sufficient; however, a sample of 136 was randomly selected from the total number of 159 general and family physicians using a random number table. Responses exceeded the required sample size and reached 136 in order to avoid any drop out, such as going on leave or sick, thereby affecting the study effect.

Verbal informed consent was obtained before administering the questionnaire. The aim of study was explained, and confidentiality and anonymity of participants were guaranteed. A total of 136 questionnaires were distributed to the selected PHC general and family physicians working in all PHC centers of the Ministry of Health (MOH), Dammam, Saudi Arabia. Completed questionnaires were collected by the principal investigator. Initially, the response rate was poor due to time restrictions and busy clinical hours; therefore, an electronic form was created and sent to the physicians using lists of their mobile numbers and they were asked to complete and return the questionnaire electronically. Frequent reminder messages were sent to non-responders with an interval of days, weeks, and up to one and a half months to increase the response rate. A meeting with the directors of PHCC was also arranged to discuss the study objectives, and to ensure the return of completed questionnaires by their selected staff. The electronic data were examined by the principal investigator immediately upon receipt, and any discrepancies in the data were discussed with the physicians concerned.

The questionnaire was coded 1 for "yes" and 0 for "no". Data were kept under lock and key to avoid any breaches of confidentiality. This study received ethical approval from the Ministry of Health, Research Committee in Dammam, Saudi Arabia. This study was not funded by any agency.

Statistical analysis. The data were analyzed using the Statistical Package for Social Sciences, version 23 (IBM SPSS Inc., Chicago, IL, USA). Frequencies and percentages of variables were computed. The Chi-square test was used for analysis of categorical data. A $p$-value $\leq 0.05$ was considered as statistically significant. The data were tested for reliability using Cronbach's alpha; the resulting coefficient was 0.707 indicating an acceptable level of reliability.

Results. The response rate to the questionnaire was $100 \%$. The demographic profile of all participants for the catch-up vaccination program in PHCC is summarized in Table 1 . In both categories, the majority

Table 1 - Demographic data of general $(n=93)$ and family physicians $(n=43)$ in primary healthcare centers in Dammam, Saudi Arabia $(n=136)$.

\begin{tabular}{|c|c|c|}
\hline Characteristics & Family physician & General physician \\
\hline \multicolumn{3}{|l|}{ Gender } \\
\hline Male & $8(18.6)$ & $34(36.6)$ \\
\hline Female & $35(81.4)$ & $59(63.4)$ \\
\hline \multicolumn{3}{|l|}{ Age } \\
\hline$<30$ years & $1 \quad(2.3)$ & $15(16.1)$ \\
\hline $30-45$ years & $38(88.4)$ & $68(73.1)$ \\
\hline $45-60$ years & $4 \quad(9.3)$ & $10(10.8)$ \\
\hline$>60$ years & 0 & 0 \\
\hline \multicolumn{3}{|l|}{ Nationality } \\
\hline Saudi & $39(90.7)$ & $86(92.5)$ \\
\hline Non-Saudi & $4 \quad(9.3)$ & $7(7.5)$ \\
\hline \multicolumn{3}{|l|}{ Position } \\
\hline Resident & $17(39.5)$ & $92(98.9)$ \\
\hline Specialist & $21(48.8)$ & $1 \quad(1.1)$ \\
\hline Consultant & $5(11.6)$ & 0 \\
\hline \multicolumn{3}{|l|}{ Degree } \\
\hline Medical degree & 8 (18.6) & $91(97.8)$ \\
\hline Family medicine diploma & $12(27.9)$ & $1(1.1)$ \\
\hline FM board or PhD & $23(53.5)$ & $1 \quad(1.1)$ \\
\hline \multicolumn{3}{|l|}{ Duration of experience(years) } \\
\hline$<5$ & $8(18.6)$ & $35(37.6)$ \\
\hline $5-10$ & $28(65.1)$ & $37(39.8)$ \\
\hline$>10$ & $7(16.3)$ & $21(22.6)$ \\
\hline \multicolumn{3}{|c|}{ Any administrative responsibilities } \\
\hline Yes & $18(41.9)$ & $12(12.9)$ \\
\hline No & $25(58.1)$ & $81(87.1)$ \\
\hline \multicolumn{3}{|c|}{ Number of clinics covered per week } \\
\hline None & 0 & $2(2.2)$ \\
\hline $1-4$ & $13(30.2)$ & $21(22.6)$ \\
\hline $5-7$ & $14(32.6)$ & $39(41.9)$ \\
\hline $8-10$ & $16(37.2)$ & $31(33.3)$ \\
\hline
\end{tabular}

Values are presented as number and percentages (\%). 
of participants were female physicians: $81.4 \%$ female versus (vs.) $18.6 \%$ male family physicians compared to $63.4 \%$ female vs. $36.6 \%$ male general physicians. Ninety percent of participants in both groups were Saudi, most participants were aged $30-45$ years, and the largest group of general physician participants were residents $(98.9 \%)$. The majority of family physicians (65.1\%) had between 5 and 10 years' experience compared to $39.8 \%$ of general physicians.

Table 2 shows the percentage of family and general physicians who reported that they have good knowledge of the catch-up vaccination program. The majority of physicians in both categories $(60 \%)$ had good knowledge with no significant difference

Table 2 - Knowledge of catch-up vaccination schedule by family $(\mathrm{n}=43)$ and general physicians $(n=93)$.

\begin{tabular}{lcccc}
\hline Knowledge & $\begin{array}{c}\text { Family } \\
\text { physicians }\end{array}$ & $\begin{array}{c}\text { General } \\
\text { physicians }\end{array}$ & $x^{2}$ & $P$-value \\
\hline Good & 60.5 & 60.2 & $0.001^{\dagger}$ & 0.98 \\
Poor & 39.5 & 39.8 & & \\
\hline \multicolumn{4}{c}{ Values are presented as percentage $(\%) .{ }^{\dagger} 0$ cells $(0.0 \%)$} & have expected \\
count less than 5. The minimum expected count is 17.07. \\
\hline
\end{tabular}

between them $\left(x^{2}=.001, p=0.98\right)$. Table 3 shows the responses of physicians on various aspects of practices related to different scenarios and statements regarding vaccination. Findings indicated that $36 \%$ of family and general physicians answered correctly to scenario $\mathrm{A}$ and no significant difference related to statements 1 and 3 was observed between the 2 categories of physicians $\left(x^{2}=2.504, \quad p=0.475\right) . \quad$ A statistically significant difference was observed between the physician groups regarding the knowledge related to the next scheduled visit after 3 months $\left(x^{2}=4.488, p=0.034\right)$. Almost two-thirds (62.5\%) of PHC physicians provide correct answers related to the statements of scenario B with no significant difference observed between physician categories $\left(x^{2}=2.531, p=0.470\right)$. There was no significant difference related to the knowledge of scenario $\mathrm{C}$ between the physician groups $\left(x^{2}=0.817, p=0.845\right)$. No significant differences in the knowledge related to the gapping of pneumococcal conjugate vaccine(PCV) $\left(x^{2}=0.611, p=0.434\right)$ and the Haemophilus influenza type $\mathrm{B}(\mathrm{HiB})$ vaccination doses were observed between physician categories $\left(x^{2}=0.141, p=0.707\right)$.

Table 3 - Percentage of correct responses to the knowledge of scenarios and statements among primary healthcare physicians (N=136).

\begin{tabular}{|c|c|c|c|c|}
\hline Statement & Family physicians & $\begin{array}{l}\text { General } \\
\text { physicians }\end{array}$ & $x^{2}$ & $P$-value \\
\hline \multicolumn{5}{|l|}{$\begin{array}{l}\text { A. Jason is a 15-month-old infant; While reviewing his immunization } \\
\text { record, you notice his vaccines are up to date through age } 6 \text { months. }\end{array}$} \\
\hline Will you give him 12 month vaccine now? & $36(83.7)$ & $79(84.9)$ & 0.034 & 0.854 \\
\hline The next scheduled visit for the child will be after 3 months? & $18(41.9)$ & $57(61.3)$ & 4.488 & 0.034 \\
\hline $\begin{array}{l}\text { The } 18 \text { month vaccine is the one that should be given at the next } \\
\text { scheduled visit? }\end{array}$ & $29(67.4)$ & $61(65.6)$ & 0.045 & 0.832 \\
\hline Total correct answers among physicians & \multicolumn{2}{|c|}{$50(36.8)$} & 2.504 & 0.475 \\
\hline \multicolumn{5}{|l|}{ B. A 9-month-old baby girl who has only received her 2-month vaccines. } \\
\hline Will you give her 9 months + 4 months without Rota now? & $36(83.7)$ & $70(75.3)$ & 1.222 & 0.269 \\
\hline The next scheduled visit will be after one month? & $35(81.4)$ & $67(72.0)$ & 1.372 & 0.242 \\
\hline $\begin{array}{l}\text { Is the } 6 \text { month vaccine without Rota the one that should be given at } \\
\text { the next visit? }\end{array}$ & $37(86.0)$ & $76(81.7)$ & .392 & 0.531 \\
\hline Total correct answers among physicians & \multicolumn{2}{|c|}{$85(62.5)$} & 2.531 & 0.470 \\
\hline \multicolumn{5}{|l|}{$\begin{array}{l}\text { C. A 5-month-old baby boy who received hep B at birth only } \\
\text { and received Hexa (IPV, DTaP, Hep B, HiB), PCV, and a Rota } \\
\text { vaccine at } 2 \text { months. }\end{array}$} \\
\hline Will you give him 4 month vaccine now? & $36(83.7)$ & $78(83.9)$ & 0.000 & 0.982 \\
\hline The next scheduled visit will be after one month? & $31(72.1)$ & $63(67.7)$ & 0.261 & 0.610 \\
\hline Is the 6 months vaccine the one that should be given at the next visit? & $39(90.7)$ & $81(87.1)$ & 0.367 & 0.544 \\
\hline Total correct answers among physicians & \multicolumn{2}{|c|}{$75(55.1)$} & 0.817 & 0.845 \\
\hline $\begin{array}{l}\text { D. A } 24 \text { month-old-baby who received the first dose of PCV vaccine } \\
\text { at the age of } 12 \text { months, are no more doses of PCV vaccine needed for } \\
\text { him? }\end{array}$ & $28(65.1)$ & $54(58.1)$ & 0.611 & 0.434 \\
\hline $\begin{array}{l}\text { E. The minimum gap between the second and third dose of } \mathrm{HiB} \\
\text { (Haemophilus influenzae type } \mathrm{B} \text { vaccine) for a baby who is } \\
\text { currently about } 10 \text { months old is } 4 \text { weeks? }\end{array}$ & $38(88.4)$ & $80(86.0)$ & 0.141 & 0.707 \\
\hline
\end{tabular}


Table 4 - Practices of family and general physicians of primary healthcare clinics in Dammam, Saudi Arabia. (N=136).

\begin{tabular}{|c|c|c|c|c|}
\hline Practices & Family physician & General physician & $x^{2}$ & $P$-value \\
\hline Do you regularly receive $\mathrm{MOH}$ memos about the vaccination program? & & & 0.283 & 0.594 \\
\hline Yes & $12(27.9)$ & $22(23.7)$ & & \\
\hline No & $31(72.1)$ & $71(76.3)$ & & \\
\hline Are you aware of the $\mathrm{MOH}$ national immunization program? & & & 0.104 & 0.746 \\
\hline Yes & $40(93.0)$ & $85(91.4)$ & & \\
\hline No & $3(7.0)$ & $8(8.6)$ & & \\
\hline Are you aware of $M O H$ catch-up vaccination schedule? & & & 0.020 & 0.886 \\
\hline Yes & $30(69.8)$ & $66(71.0)$ & & \\
\hline No & $13(30.2)$ & $27(29.0)$ & & \\
\hline Did you train or attend an educational lecture on vaccination? & & & 7.565 & 0.006 \\
\hline Yes & $23(53.5)$ & $27(29.0)$ & & \\
\hline No & $20(46.5)$ & $66(71.0)$ & & \\
\hline Do you see paediatric patients younger than 5 years? & & & 5.675 & 0.017 \\
\hline Yes & $36(83.7)$ & $89(95.7)$ & & \\
\hline No & $7(16.3)$ & $4(4.3)$ & & \\
\hline Have you seen a child with a delayed vaccination schedule? & & & 1.687 & 0.194 \\
\hline Yes & $38(88.4)$ & $88(94.6)$ & & \\
\hline No & $5(11.6)$ & $5(5.4)$ & & \\
\hline Do you advise parents to keep up a vaccine program for their child? & & & 1.934 & .164 \\
\hline Yes & $40(93.0)$ & $91(97.8)$ & & \\
\hline No & $3(7.0)$ & $2(2.2)$ & & \\
\hline Do you feel confident dealing with catch-up vaccination? & & & 0.191 & 0.662 \\
\hline Yes & $23(53.5)$ & $46(49.5)$ & & \\
\hline No & $20(46.5)$ & $47(50.5)$ & & \\
\hline
\end{tabular}

Table 4 shows information regarding the vaccination practices of family and general physicians in PHC clinics. A statistically significant difference between physician groups was observed on the question related to training or attending an educational lecture in vaccination program between family and general physicians $\left(x^{2}=7.565, p=0.01\right)$ and indicated that $53 \%$ of family physicians attended training or educational lectures compared to $29 \%$ of general physicians. A higher proportion of general physicians (95.7\%) reported seeing pediatric patients aged $<5$ years than family physicians $(83.7 \%)\left(x^{2}=5.675, p=0.02\right)$.

Table 5 shows no significant differences in the factors influencing the practices related to the implementation of the catch-up vaccination program between the 2 categories of physicians in PHC centers. However, a significant difference was observed related to more involvement of general physicians $(80.3 \%$ ) in vaccination programs compared to family physicians $(19.7 \%)$ in the implementation of the catch-up vaccination program in PHC centers $\left(x^{2}=8.428, p=0.004\right)$.

Discussion. Acceptance of vaccination programs among the general population depends largely on motivation by the healthcare system. The PHCC based on PHC physicians constitute an important segment of the primary healthcare system for the provision of preventive health services. The level of vaccination services provided by them to their catchment population is directly related to their level of knowledge and the practices in their centers. Therefore, in order to ensure that the catch-up vaccination program is successful, the assessment of existing knowledge, practices, and factors influencing their practices in the implementation of the vaccination program is essential in order to identify any deficiencies if present, and address them by adequate training and orientation in program practices. This study was undertaken with the family and general physicians, their responses were recorded, and conclusions were drawn.

In the current study, the majority of physicians were female $(81.4 \%)$ of family physicians and $63.4 \%$ of general physicians. The largest group of general physicians were residents (99\%). This may explain why the Saudi Commission of Health and Specialty increased the number of acceptance into family board programs to meet the Saudi Arabia 2030 vision of the healthcare system. The majority of family physicians $(65.1 \%)$ had between 5-10 years of experience compared to $39.8 \%$ of general physicians. 
Table 5 - Factors influencing the implementation of the catch-up vaccination program in primary healthcare centers $(\mathrm{N}=136)$.

\begin{tabular}{|c|c|c|c|c|}
\hline Practices & Family physicians & General physician $s$ & $\mathrm{X}^{2}$ & $P$-value \\
\hline Does your center cover vaccine cases? & & & 1.418 & .234 \\
\hline Yes & $43(32.3)$ & $90(67.7)$ & & \\
\hline No & 0 & $3(100)$ & & \\
\hline Does the vaccine clinic in your center have all vaccine shots? & & & 0.121 & 0.728 \\
\hline Yes & $38(31.1)$ & 84 (68.9) & & \\
\hline No & $5(35.7)$ & $9(64.3)$ & & \\
\hline Are all vaccinations available in primary health center? & & & 0.311 & 0.577 \\
\hline Yes & $38(30.9)$ & $85(69.1)$ & & \\
\hline No & $5(38.5)$ & $8(61.5)$ & & \\
\hline Are you involved in the vaccination program in PHC center? & & & 8.428 & 0.004 \\
\hline Yes & $13(19.7)$ & $53(80.3)$ & & \\
\hline No & $30(42.9)$ & $40(57.1)$ & & \\
\hline Do you give the vaccine to a child by yourself? & & & 0.482 & 0.488 \\
\hline Yes & $8(38.1)$ & $13(61.9)$ & & \\
\hline No & $35(30.4)$ & $80(69.6)$ & & \\
\hline Do you follow up with catch-up vaccine cases in your center? & & & 0.678 & 0.410 \\
\hline Yes & $27(29.3)$ & $65(70.7)$ & & \\
\hline No & $16(36.4)$ & $28(63.6)$ & & \\
\hline have you been asked to formulate catch-up vaccine schedules? & & & 0.505 & 0.478 \\
\hline Yes & $25(34.2)$ & $48(65.8)$ & & \\
\hline No & $18(28.6)$ & $45(71.4)$ & & \\
\hline Do you think that formulating catch-up vaccine schedules is difficult & & & 3.586 & 0.058 \\
\hline Yes & $26(39.4)$ & $40(60.6)$ & & \\
\hline No & $17(24.3)$ & $53(75.7)$ & & \\
\hline
\end{tabular}

The study results revealed that $60 \%$ of PHC physicians have good knowledge of the catch-up vaccination program and its implementation in their practices with no statistically significant difference between family and general physicians in the knowledge of the catch-up vaccination schedule. This study found a level of knowledge $40 \%$ higher than that reported by Cohen et al. ${ }^{13}$ Findings indicated that, overall, $36.8 \%$ of PHC physicians correctly responded to the statements in scenario A, $62.5 \%$ responded correctly to the statements in scenario B and $55.1 \%$ responded correctly to the statements in scenario C. However, in scenario A, a lower correct response rate related to the scheduling of the 18-month vaccination for children $\geq 15$ months of age was found for family physicians. Similar results were found by Cohen et a $\mathrm{l}^{13}$ and Wood et al. ${ }^{16}$ This difference in knowledge could be attributed to more involvement of general physicians in vaccination programs compared to family physicians. Similar results have been seen in a study conducted by Cohen et al. ${ }^{13}$ In Chicago-based study, family physicians were less likely to follow a catch-up vaccination program compared to pediatricians.

Our study results indicated that family physicians were more involved in educational lectures and administrative tasks compared to general physicians who were involved in the implementation of the catch-up vaccination program. No significant difference was observed between the 2 physician categories in relation to the knowledge of PCV and Haemophilus influenza type B (Hib) vaccine gapping. Findings revealed that $65.1 \%$ of family physicians responded correctly to the gapping of PCV vaccine compared to $58.1 \%$ of family physicians and $88.4 \%$ of family physicians responded correctly to the gapping of Haemophilus influenza type B (Hib) vaccine compared to $86 \%$ of general physicians.

This study also highlighted the possible factors that influence the practice of implementing a catch-up vaccination program. The most important factor affecting the catch-up vaccination program was more involvement of (80.3\%) of general physicians, compared to family physicians (19.7\%). This result is similar to that reported by Cohen et al. ${ }^{13}$

The strengths of our study include a high response rate $(100 \%)$ among PHC physicians as gatekeepers of primary care services and, to the best of our knowledge, no similar study has previously been carried out in Saudi Arabia. Despite the study's results; however, all of the information reported may not reflect the actual situation in the PHC clinics; our questionnaire contains closed-ended questions that may not have identified 
important points in the knowledge, procedures, and factors influencing the practices at PHC clinics. In our study, more general physicians were selected compared to family physicians; therefore, it is difficult to generalize our results and conduct comparisons between the 2 physician categories. A larger sample of family physicians would be required to make a valid comparison of the differences between the 2 categories. This study did not address the influence of each factor on the outcome. However, we have explained the combined impact of all the factors on the outcome of the study, and therefore, where we did not consider multiple logistic regression.

In addition to tight legislation and public health education, a high level of knowledge and appropriate measures for immunization practices among healthcare providers must be ensured to achieve a high level of vaccine coverage. This study suggests the need for more training and educational interventions on the vaccination program for general physicians in PHC centers in Dammam, as the majority of them encounter catch-up vaccination cases on a daily basis. Such training will serve to keep them updated and will help to avoid any lapses in scheduling vaccinations for children. It is also recommended that more family physicians should be involved in the vaccination program to ensure good practices in order to meet the expectations presented by Saudi Arabia's Vision 2030 in providing high quality of health services. ${ }^{17}$

Further investigation is needed to assess the efficacy of such interventions for improving immunization behaviors.

In conclusion, PHC physicians in Dammam, Saudi Arabia, are fairly knowledgeable on the catch-up vaccination schedule. General physicians were found to be knowledgeable due to their involvement in the vaccination program, while family physicians were knowledgeable due to attending training or lectures regarding the vaccination program. However, some lack of knowledge related to scheduling the 18-month vaccine was observed among family physicians.

Acknowledgment. The authors gratefully Eiditae (www.editage.com) for English language editing.

\section{References}

1. Ministry of Health. MOH Publication - Report on Measles in the Middle East. [Updated 2013. Cited 2017 November 9]. Available from URL: https://www.moh. gov.sa/en/Ministry/MediaCenter/Publications/Pages/ Publications-2013-05-04-002.aspx
2. World Health Organization. World Immunization Week 2017. [Updated 2017. Cited 2017 October 29]; Available from URL: http://www.who.int/campaigns/immunization-week/2017/ event/en/

3. World Health Organization. WHO | Immunization coverage. [Updated 2017. Cited 2017 Oct 29]; Available from: http:// www.who.int/mediacentre/factsheets/fs378/en/

4. Wood D, Halfon N, Pereyra M, Hamlin JS, Grabowsky M. Knowledge of the childhood immunization schedule and of contra indications to vaccinate by private and public providers in Los Angeles. Pediatr Infect Dis J 1996; 15: 140-145.

5. Ministry of Health. Ministry News - 'New Vaccines Added to the National Immunization Schedule'. [Updated 2013. Cited 2017 October 29]. Available from: https://www.moh.gov.sa/en/ ministry/mediacenter/news/pages/news-2013-07-24-002.aspx

6. Tufenkeji H, Rattan H. Childhood immunization in the Kingdom of Saudi Arabia. Ann Saudi Med 1994; 14: 91-93.

7. Hasanain FH, Jan MM. Delays in primary vaccination of infants living in Western Saudi Arabia. Saudi Med J 2002; 23 : 1087-1089.

8. Esposito S, Principi N, Cornaglia G. Barriers to the vaccination of children and adolescents and possible solutions. Clin Microbiol Infect 2014; 20: 25-31.

9. Nicoll A, Elliman D, Begg NT. Immnunisation: causes of failure and strategies and tactics for success strong professional commitment is the key. BMJ 1989; 299: 808-812.

10. Rashid AKMH. Childhood immunization status related to social and educational status of parents in a peripheral northern town of Saudi Arabia. Ann Saudi Med 1993; 13: 335-339.

11. Ministry of Health. Health Days 2015 - World Immunization Week. [Updated 2015. Cited 2017 November 6]. Available from: https://www.moh.gov.sa/en/HealthAwareness/ healthDay/2015/Pages/HealthDay-2015-04-24.aspx

12. Al-Ayed IH, Sheik S. Knowledge and practices of childhood immunization among primary health care providers in Riyadh City: Part I: Handling and administration of vaccines. J Family Community Med 2006; 13: 19-24.

13. Al-Ayed IH, Sheik S. Knowledge \& practices of childhood immunization among primary health care providers in Riyadh city: part ii - precautions and contraindications to vaccination. J Family Community Med 2006; 13: 19-24.

14. Engineer FG, Keskinocak P, Pickering LK. Catch-up scheduling for childhood vaccination. Oper Res 2009; 57: 1307-1319.

15. Cohen NJ, Lauderdale DS, Shete PB, Seal JB, Daum RS. Physician knowledge of catch-up regimens and contraindications for childhood immunizations. Pediatrics 2003; 111: 925-932.

16. Wood D, Halfon N, Pereyra M, Hamlin JS, Grabowsky M. Knowledge of the childhood immunization schedule and of contraindications to vaccinate by private and public providers in Los Angeles. Pediatr Infect Dis J 1996; 15: 140-145.

17. Vison 2030 Kingdom of Saudi Arabia. [Updated 2016. Cited 2019 November 29]. Available from URL: https://vision2030. gov.sa/sites/default/files/report/Saudi_Vision2030_EN_2017. pdf 